\title{
Comparison of neural networks and regression time series in estimating the Czech Republic and China trade balance
}

\author{
Zuzana Rowland ${ }^{1,{ }^{*}}$ Petr $\breve{S}$ leř ${ }^{1}$ and Marek Vochozka ${ }^{1}$ \\ ${ }^{1}$ Institute of Technology and Business in České Budějovice, School of Expertness and Valuation, \\ Okružní 517/10, 37001 České Budějovice, Czech Republic
}

\begin{abstract}
Foreign trade has been and is considered to be very important. Trade balance measurement provides one of the best analyzes of a country's external economic relations. It serves as a monetary expression of economic transactions between a certain country and its foreign partners over a certain period. The aim of this paper is to compare the accuracy of time series alignment by means of regression analysis and neural networks on the example of the trade balance of the Czech Republic and the People's Republic of China. Trade balance data between the Czech Republic and the People's Republic of China is used. This is a monthly balance starting in 2000 and ending in July 2018. First, a linear regression is made followed by regression using artificial neural networks. A comparison of both methods at expert level and experience of the evaluator, the economist, is performed. Optically, the LOWESS curve appears to be best out of the linear regression and the fifth preserved RBF 1-24-1 network seems the mot appropriate out of neural networks.
\end{abstract}

Key words: neural networks, regression analysis, comparison, trade balance, prediction

\section{Introduction}

Foreign trades have always been considered to be of the utmost importance and have always been given great attention. The balance of payments is recognized as an instrument that provides one of the best analyzes of a country's external economic relations and serves as a monetary expression of economic transactions between a country and its foreign partners over a certain period [1].

We can define the balance of payments as a systematic statistical record that captures all economic transactions between domestic and foreign currencies for a certain period of time. It includes transactions related to the movement of goods, services and earnings, operations with financial receivables and payables and operations referred to as transfers [2]. The balance of payments consists of two basic accounts, a current account and a capital account [3]. The current account of the balance of payments reflects the movement of real resources (eg goods, services, transfers, etc.), the capital account mainly depicts the international

\footnotetext{
* Corresponding author: rowland@mail.vstecb.cz
} 
movement of capital - direct and portfolio investment, short-term capital, etc. [4]. The difference between a current account movement and a movement on a capital account is reflected in the change in foreign currency reserves. If the current account liability is not covered by the asset in the capital account, the central bank's foreign currency reserves will be reduced and vice versa [5].

Regarding the development of the balance of payments of the Czech Republic and China, the Czech Republic has several advantages from the commercial point of view of China. Thanks to its geographical position, the Czech Republic is very close to the Western markets, especially to neighboring Germany, the country is politically stable and is actively engaged in business transactions within the European Union, which gives the Chinese market additional opportunities [6]. The fragmentation of world production and the higher foreign value of Czech exports allow Chinese exports with added value to reach western markets through the Czech Republic [7].

China is the 4th largest trading partner for the Czech Republic and the second largest importer (since 2006). For the Czech Republic, China is the 18th largest export market. Czech exports to China have a growing trend over the long term. The largest increases were recorded in 2007 (by almost 60\%) and in 2010 (53\%). The increase was also high in 2011, when it was more than 30\%. In 2012 and 2013 growth stood at 8-11\%. Exports have tripled since 2007. In the past five years, they have grown by about $70 \%$ [8]. In 2017, exports from the Czech Republic to China reached 56 billion CZK, which represents a yearly increase of $20 \%$ and historically record exports from the Czech Republic to China. China is one of the largest but also the most demanding markets in the world [9]. Business is characterized by innumerable barriers, hard competition, and unusual environments for Europeans. Nevertheless, Czech exporters succeed in promoting themselves in the Chinese market [10]. In 2014, Czech exports to China amounted to 42.5 billion CZK. China imports to the Czech Republic in 2017 amounted to 473 billion CZK (y/y $+10 \%)$. The main position in Czech exports to China has long been occupied by machines and transport vehicles, which make up more than half of direct exports [9]. Evidence of a large increase in profits in the automotive industry is the latest investment of the Chinese automotive company Yanfeng in Planá nad Lužnicí, which has released 1.85 billion CZK for car production. The project is designed to create almost 600 jobs [11]. The software industry is also considered by the Chinese government to be necessary for economic progress and profit [12]. However, we must not forget the biggest problem of Czech-Chinese trade relations, which despite the economic progress remains at high deficit on the Czech side. According to the statistics mentioned above, the Czech Republic's deficit in 2017 amounted to International trade is an important factor in economic growth. In order for the Czech Republic to maintain its foreign relations with China, it is essential that it continue to invest in science and research. [13]. Sustainability of trade with China is mainly dependent on comparative advantages. The most cost-effective comparative advantage of China is the cheap cost factors in which we can include cheap labor in large quantities [14]. Thanks to the political transformation, the Czech Republic has incorporated the qualitative comparative advantage we can see in the industrial sectors [15]. The Czech Republic should invest in education, which will allow employees with knowledge of the Chinese market to be recruited. It should also look for opportunities in the development trends of China's economy and culture, and fight against the threatening factors of low market flexibility and high spending on research and development. The development of trade and economic cooperation between the Czech Republic and China depends, in particular, on the technical progress and innovation that the Czech Republic must continue to develop. 


\section{Data and methods}

Data for analysis is available on the website of the World Bank etc. The data on the trade balance between the Czech Republic and the People's Republic of China will be used for the analysis. This will be the difference between total exports and imports between the two countries from the Czech point of view. The time period for which the data will be available is the monthly balance starting from January 2000 and ending in July 2018. This is about 223 input data. The unit is the Euro.

The descriptive characteristics of the data are given in Table 1.

Table 1. Characteristics of the data file

\begin{tabular}{|l|r|r|}
\hline Samples & Month (Input variable) & \multicolumn{1}{c|}{ Balance (Output (goal)) } \\
\hline Minimum (Training) & 36526.00 & $-1.050893 \mathrm{E}+09$ \\
\hline Maximum (Training) & 43252.00 & $-4.054250 \mathrm{E}+07$ \\
\hline Average (Training) & 39916.52 & $-3.661027 \mathrm{E}+08$ \\
\hline Standard deviation (Training) & 1949.82 & $2.289766 \mathrm{E}+08$ \\
\hline Minimum (Testing) & 36586.00 & $-9.687806 \mathrm{E}+08$ \\
\hline Maximum (Testing) & 43282.00 & $-5.088367 \mathrm{E}+07$ \\
\hline Average (Testing) & 39702.30 & $-3.679126 \mathrm{E}+08$ \\
\hline Standard deviation (Testing) & 2174.13 & $2.719910 \mathrm{E}+08$ \\
\hline Minimum (Validation) & 36951.00 & $-1.168102 \mathrm{E}+09$ \\
\hline Maximum (Validation) & 43040.00 & $-6.679944 \mathrm{E}+07$ \\
\hline Average (Validation) & 40047.88 & $-3.945945 \mathrm{E}+08$ \\
\hline Standard deviation (Validation) & 3096.16 & $3.098454 \mathrm{E}+08$ \\
\hline Minimum (Overall) & 36526.00 & $-1.168102 \mathrm{E}+09$ \\
\hline Maximum (Overall) & 43282.00 & $-4.054250 \mathrm{E}+07$ \\
\hline Average (Overall) & 39904.26 & $-3.705868 \mathrm{E}+08$ \\
\hline Standard deviation (Overall) & 1963.77 & $2.400326 \mathrm{E}+08$ \\
\hline
\end{tabular}

Source: Authors.

Interesting, of course, is price development over time. Figure 1 therefore shows the selected statistical characteristics in graphical form, including the histogram of the input data. 


\section{Summary; Balance}


Summary statistic s:Balance $N$ vald $=223,000000$

Average $=370586786,789237$

Minimumf 1168101644,000000

Maximum $=40542502,000000$

Stand. dev $.=240032601,782945$

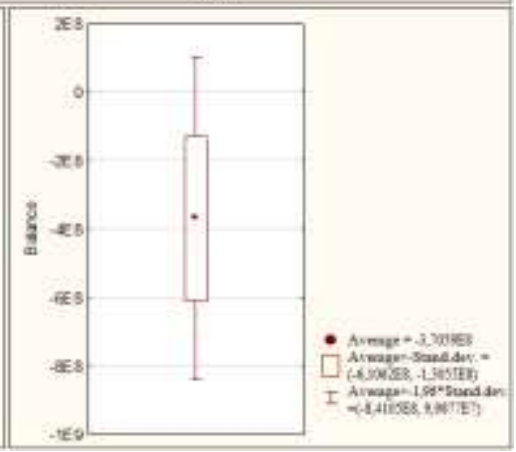

Fig. 1. Graph of basic statistical characteristics

Source: Authors.

For data processing, DELL's Statistica version 12 will be used. First, a linear regression will be performed. Afterwards, neural networks will be used for regression.

Linear regression will be performed on the monitored data sample for the following functions:

- Linear,

- Polynomial,

- Logarithmic,

- Exponential,

- Multiparameter of weighed distances,

- Multiparameter negative-exponential smoothing.

First, the correlation coefficient, ie the dependence of trade balance on time, will be calculated. Next, we will work with a level of significance of 0.95 .

Then regression will be performed using neural structures. We will generate multilayer perceptron networks and neural networks of basic radial functions. Time will be the independent variable. We will determine the trade balance between the Czech Republic and the PRC as the dependent variable. We divide the time series into three sets - training, testing, and validation. The first group will have $70 \%$ of input data. Based on the training set of data, we generate neural structures. In the remaining two sets of data, we always leave $15 \%$ of the input information. Both groups will serve us to verify the reliability of the found neural structure, or the found model. The delay of the time series will be 1 . We will generate 10,000 neural networks. We will preserve 5 of them with the best characteristics. We will be orientated using the smallest square method. We will terminate network generation if there is no improvement, ie to reduce the sum of squares. Thus, we will preserve those neural structures whose sum of squares of residue to the actual Czech 
Republic and PRC trade balance will be as low as possible (ideally zero). In the hidden layer, we will have at least two neurons, at most 50. In the case of the radial basic function, there will be at least 21 neurons in the hidden layer, at most 30. For the multiple perceptron network we will consider these distribution functions in the hidden layer and in the output layer:

- Linear,

- Logistic,

- Atanh,

- Exponential,

- Sinus.

Other settings are left by default (using the ANS tool - automated neural network).

In conclusion, we compare the results of linear regression and regression using neural networks. Comparison will not take place in the form of residue analysis (minimum, maximum values, spread of residues, etc.), but at expert level and experience of the assessor, economist.

\section{Results}

\section{Linear regression}

The correlation coefficient is -0.8830 , which represents a significant statistical indirect dependence of the trade balance on the development over time. The determination coeficient reaches 0.7797 .

A point graph was constructed (see Figure 2), where the points were intersected by a regression curve, in this case linear. The line parameters are shown in the figure.



Fig. 2. The Czech Rep. and the PRC point graph intersected by the regression curve - linear curve Source: Authors.

The solid line represents the regression function. The linear functions, however, do not fully respect the trade balance of the Czech Republic and the PRC. Figure 3 represents the intersection of the point graph with a polynomial function. 


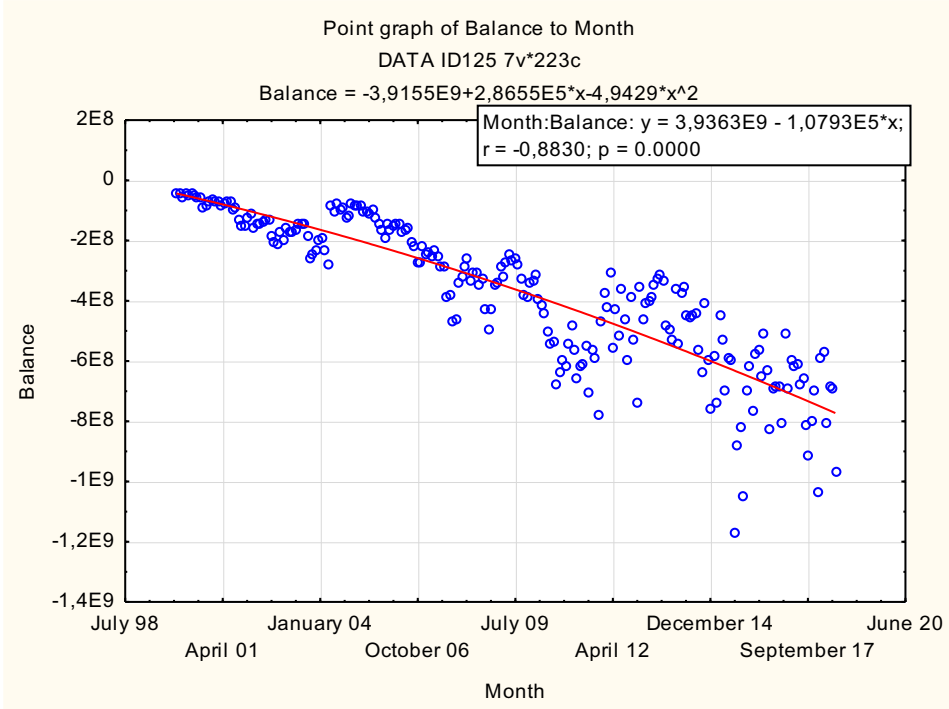

Fig. 3. The Czech Rep. and the PRC trade balance point graph intersected by a regression curve polynomial function

Source: Authors.

Even in this case, the solid line represents a regression curve. Its shape resembles a straight line, a linear function. Even in this case, the trade balance of the partner countries is not fully represented.

Figure 4 shows a point graph intersected by a logarithmic function.

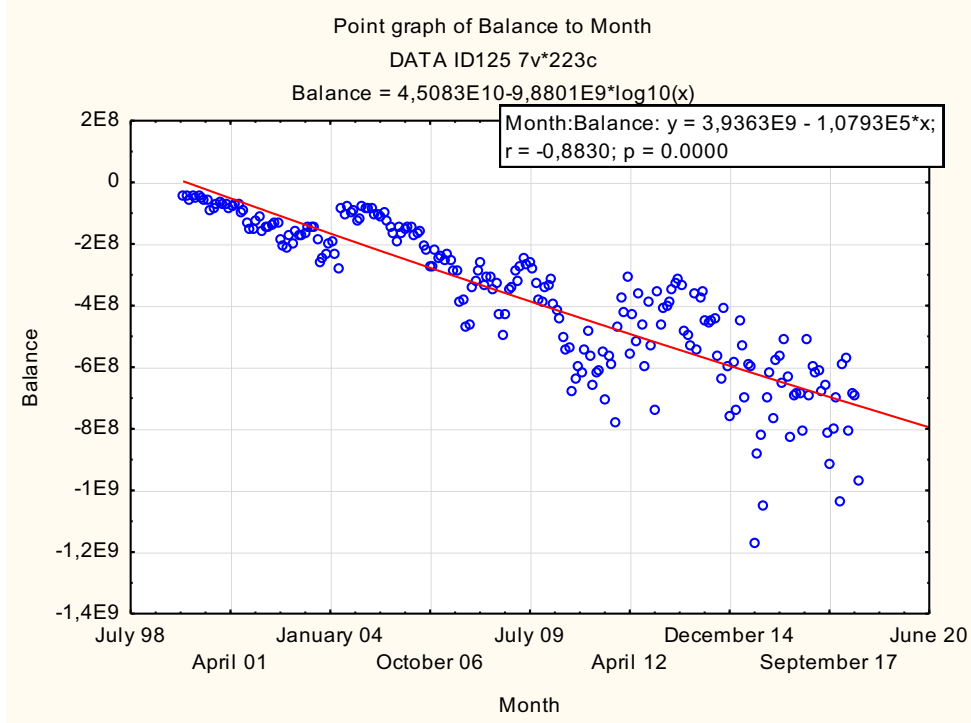

Fig. 4. The Czech Rep. and PRC trade balance point graph intersected by a regression curve logarithmic function

Source: Authors. 
The logarithmic function curve also closely resembles a straight line and therefore a linear function. From the location of individual points in the graph, it is obvious that the logarithmic function is not suitable for regression.

Figure 5 provides a graph of the trade balance of the Czech Republic and the PRC intersected by the LOWESS function.

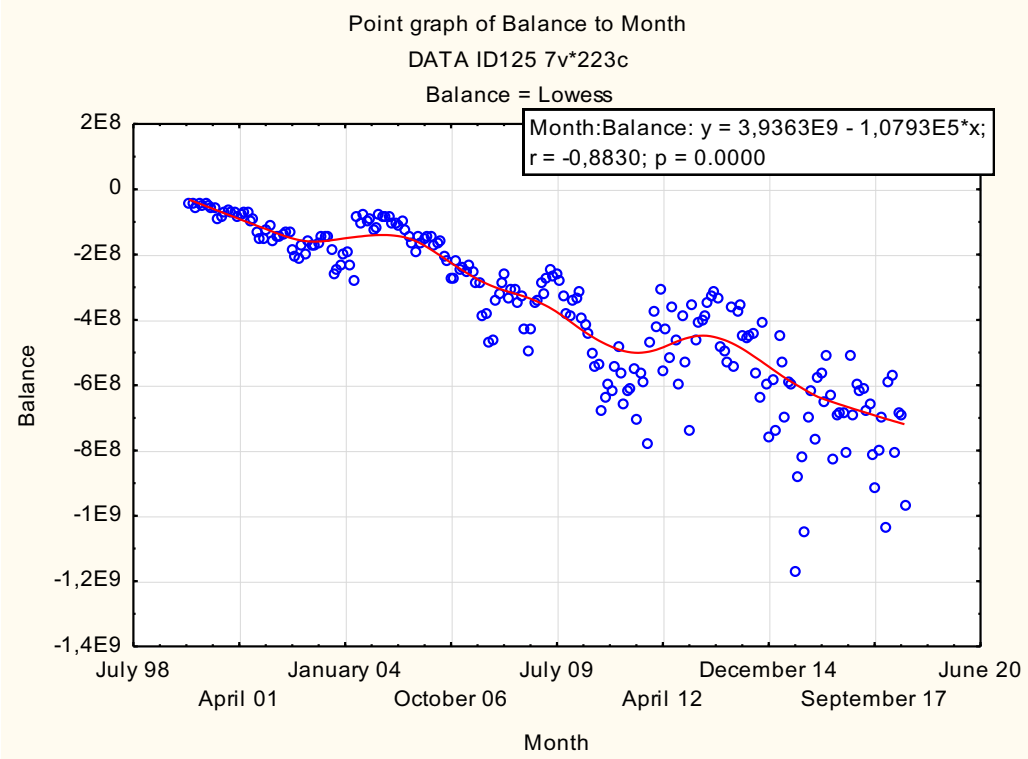

Fig. 5. The Czech Rep. and the PRC trade balance point graph intersected by a regression curve LOWESS

Source: Authors.

The LOWESS (locally weighted scatterplot smoothing) function, or LOES (locally estimated scatterplot smoothing), is calculated as a regression function at partial intervals. The LOWESS curve aligns the time series and monitors its trend appropriately. The LOWESS curve intersection looks very interesting. It can fairly reveal the trend of the trade balance of the partner countries.

Figure 6 provides a point graph of the Czech Republic and PRC trade balance, intersected by smallest squares of weighed distances function. 


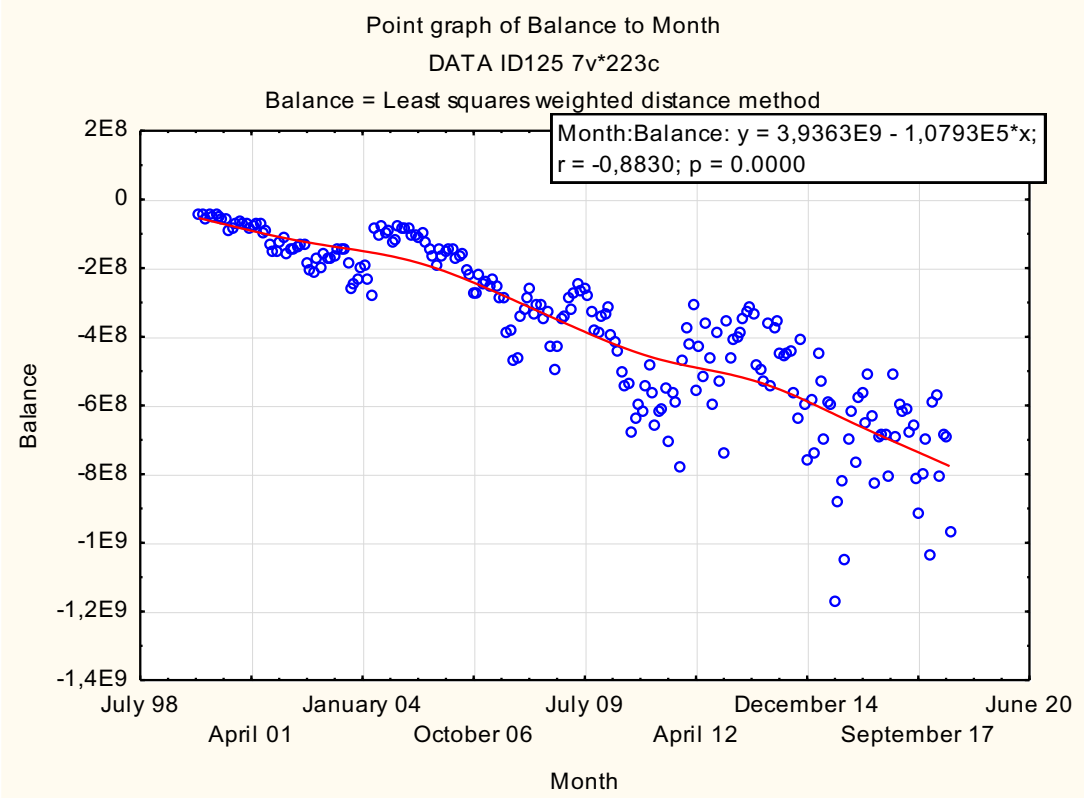

Fig. 6. Czech Rep and PRC trade balance point graph intersected by the regression curve - sm. sq. of weighed distances

Source: Authors.

The curve copies the development of trade balance over its entire interval better than linear functions, polynomial functions and logarithmic functions.

Figure 7 provides the intersection of the function obtained by smallest squares of negative - exponential smoothing.

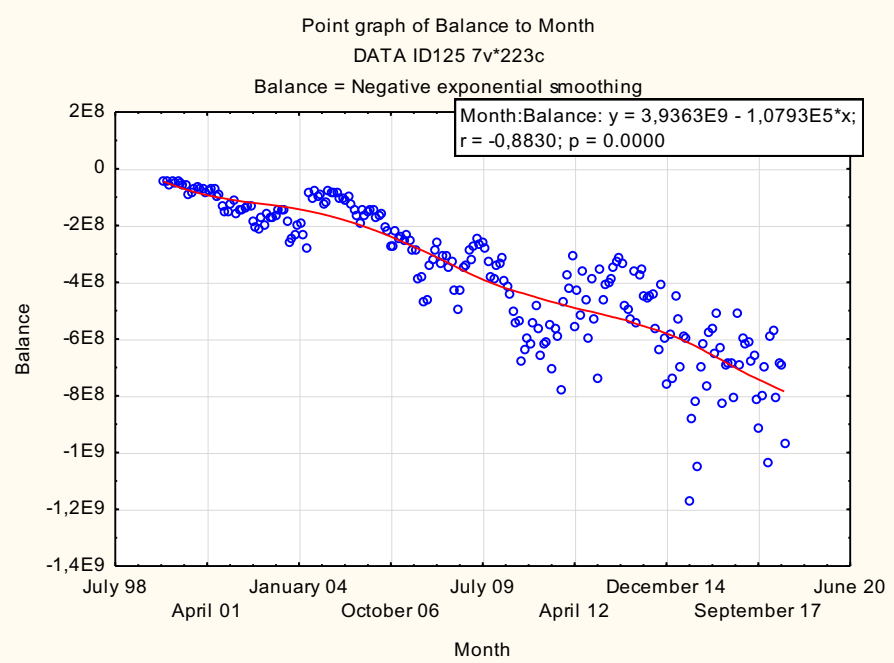

Fig. 7. $\mathrm{CZ}$ and PRC trade balance point graph intersected by a regression curve - sm. sq. negative exponential smoothing

Source: Authors. 
Even this curve appears to be interesting and appropriate for a possible prediction. It also has better results than linear, polynomial, and logarithmic.

The correlation coefficient indicates significant statistical indirect dependence of the target variable on time development. Its value is -0.8830 . The determination coefficient is 0.7797. If we only evaluated the results by comparing the trade balance between the Czech Republic and the PRC and the shape of the regression curve and taking into account a simple linear regression, we could certainly say that the LOWESS curve is closest to the development. Following it are curves obtained by the smallest squares method, namely negative-exponential smoothing and weighed distances. All three copy the basic trade balance between the Czech Republic and the PRC. At the same time, it should be recognized that the other functions (linear functions, polynomial functions, and logarithmic functions) are not suitable for time series alignment. It will simplify its course too much.

\section{Neural structures}

Based on the established procedure, 10,000 neural networks were generated. Five networks have been preserved, the ones showing the best parameters. Their overview is given in Table 2.

Table 2. Overview of preserved neural networks

\begin{tabular}{|c|c|c|c|c|c|c|c|c|c|c|}
\hline \begin{tabular}{|c|} 
Net. \\
name
\end{tabular} & $\begin{array}{l}\text { Train. } \\
\text { perf. }\end{array}$ & $\begin{array}{l}\text { Test. } \\
\text { perf. }\end{array}$ & $\begin{array}{l}\text { Valid. } \\
\text { perf. }\end{array}$ & $\begin{array}{l}\text { Train. } \\
\text { error }\end{array}$ & $\begin{array}{l}\text { Test. } \\
\text { error }\end{array}$ & $\begin{array}{l}\text { Valid. } \\
\text { error }\end{array}$ & $\begin{array}{l}\text { Train. } \\
\text { algorit. }\end{array}$ & $\begin{array}{l}\text { Error } \\
\text { function }\end{array}$ & $\begin{array}{c}\text { Activ. } \\
\text { of hidd. } \\
\text { lyr. }\end{array}$ & $\begin{array}{l}\text { Output } \\
\text { activ. } \\
\text { funct. }\end{array}$ \\
\hline$\overline{\mathrm{RB}}$ & & 9426 & 4 & $\mathrm{E}$ & & & & sq. & jau & dent \\
\hline RBI & & & 2 & $\begin{array}{r}5.208 \\
\mathrm{E}\end{array}$ & & & & $\begin{array}{r}\mathrm{im} \text { of } \\
\text { sq. }\end{array}$ & Gaus & \\
\hline \begin{tabular}{|c|} 
RBF \\
$1-30-1$
\end{tabular} & 0 & 3705 & .9505 & $\begin{array}{r}4.046748 \\
E+15\end{array}$ & $\begin{array}{r}8.9651 \\
70 \mathrm{E}+15 \\
\end{array}$ & \begin{tabular}{|r|}
5.6887 \\
$61 \mathrm{E}+15$ \\
\end{tabular} & RBF? & $\begin{array}{r}\text { um of } \\
\text { sq. }\end{array}$ & Gauss & - \\
\hline \begin{tabular}{|c|} 
RBF \\
$1-27-1$ \\
\end{tabular} & 252 & 9042 & 9 & $\begin{array}{r}3.7015 \\
\mathrm{E}+ \\
\end{array}$ & $\begin{array}{r}6.9056 \\
36 \mathrm{E}+15 \\
\end{array}$ & \begin{tabular}{|r|}
4.2726 \\
$54 \mathrm{E}+15$ \\
\end{tabular} & DI & $\begin{array}{r}\text { um of } \\
\text { sq. }\end{array}$ & & \\
\hline \begin{tabular}{|c|} 
RBF \\
$1-25-1$ \\
\end{tabular} & 0.8720 & & & $\begin{array}{r}87141 \\
\mathrm{E}+15 \\
\end{array}$ & $\begin{array}{r}5.7671 \\
00 \mathrm{E}+15 \\
\end{array}$ & \begin{tabular}{|r|}
4.7584 \\
$36 \mathrm{E}+15$ \\
\end{tabular} & (1) & & rauss & fuctitut? \\
\hline
\end{tabular}

Source: Authors.

These are only the neural networks of the basic radial function. The input layer has only one variable - time. In the hidden layer, neural networks contain from 22 to 30 neurons. In the output layer, we have a single neuron and the only output variable is the export balance of the Czech Republic and the PRC. For all networks, the RBFT training algorithm was applied. In addition, all neural structures used the same function to activate the hidden layer of neurons, namely the Gaussian curve. They also use the same function to activate the outer layer of neurons, and this function is identity (see Table 2).

Training, testing and validation performance is also interesting. In general, we are looking for a network that has the same performance in all sets of data (we remind that the data was randomly distributed). The error should be as small as possible. As far as the error is concerned, it should be recalled that we are working on the balance expressed in euros, ie with a great deal of detail, which will also correspond to the above-calculated error.

The performance of individual sets of data is expressed as a correlation coefficient. The values of the individual data sets according to specific neural networks are presented in Table 3. 
Table 3. Correlation coefficients of individual data sets

\begin{tabular}{|l|r|r|r|}
\hline & Balance (Training) & Balance (Testing) & \multicolumn{1}{|c|}{ Balance (Validation) } \\
\hline 1.RBF 1-22-1 & 0.943854 & 0.942643 & 0.953409 \\
\hline 2.RBF 1-24-1 & 0.893296 & 0.855999 & 0.951235 \\
\hline 3.RBF 1-30-1 & 0.917891 & 0.870478 & 0.950481 \\
\hline 4.RBF 1-27-1 & 0.925175 & 0.904176 & 0.959754 \\
\hline 5.RBF 1-25-1 & 0.942461 & 0.928905 & 0.949845 \\
\hline
\end{tabular}

Source: Authors.

The table shows that the performance of all stored neuronal structures is very high. Higher fluctuations in the performance of the individual datasets are shown in networks 2. RBF1-21-1 and 3. RBF 1-29-1. The correlation coefficient of all training data sets ranges from more than 0.89 to over 0.94 . The value of the correlation coefficient of the testing data sets for all neural networks ranges from more than 0.85 to over 0.94 . The correlation coefficient of the validation data set of all neural networks is above the 0.949 level. In order to select the most suitable neural structure, we need to analyze the results obtained. Table 4 provides the basic statistical characteristics of each set of data for all neural structures.

Table 4. Statistics of individual data sets according to preserved neural structures

\begin{tabular}{|c|c|c|c|c|c|}
\hline Statistics & 1.RBF & 2.RBF & 3.RBF & 4.RBF & 5.RBF \\
\hline Minimum prediction (Training) & -898391801 & -821663096 & -857909633 & -914757095 & -905237832 \\
\hline Maximum prediction (Training) & -49086981 & -40172975 & -13537671 & -4452348 & -41323566 \\
\hline Minimum prediction (Testing) & -789576394 & -804782911 & -828736787 & -706475950 & -744790331 \\
\hline Maximum prediction (Testing) & -49635722 & -66639725 & -23270632 & -73460448 & -55363423 \\
\hline Minimum prediction (Validation) & -803294038 & -842962423 & -777155961 & -816475698 & -807210541 \\
\hline Maximum prediction (Validation) & -79169241 & -72858834 & -16165433 & -68026809 & -85082148 \\
\hline Minimum residues (Training) & -336438354 & -427989158 & -399848725 & -377532214 & -373817164 \\
\hline Maximum residues (Training) & 258520249 & 277584103 & 188100987 & 225393996 & 210531734 \\
\hline Minimum residues (Testing) & -252876501 & -563851527 & -352153219 & -283794827 & -333348153 \\
\hline Maximum residues (Testing) & 208414123 & 238241010 & 163190692 & 208652287 & 135282887 \\
\hline Minimum residues (Validation) & -364807606 & -325139221 & -390945683 & -351625946 & -360891103 \\
\hline Maximum residues (Validation) & 146675635 & 131088493 & 100813927 & 75309342 & 141610295 \\
\hline Minimum standard residues (Training) & -6 & -6 & -6 & -6 & -7 \\
\hline Maximum standard residues (Training) & 5 & 4 & 3 & 4 & 4 \\
\hline Minimum standard residues (Testing) & -4 & -6 & -4 & -3 & -4 \\
\hline Maximum standard residues (Testing) & 3 & 2 & 2 & 3 & 2 \\
\hline Minimum standard residues (Validation) & -5 & -5 & -5 & -5 & -5 \\
\hline Maximum standard residues (Validation) & 2 & 2 & 1 & 1 & 2 \\
\hline
\end{tabular}

Source: Authors.

Ideally, the individual statistics of the neural network are cross-sectional in all sets (minimum, maximum, residue, etc.). However, in the case of the aligned time series, the differences are noticeable. They are apparent both between individual datasets of one neural network and between individual neural networks. Somewhat larger differences are reflected in the residue characteristics. However, we are not able to clearly identify which of the preserved neural networks has the most appropriate results.

Figure 8 is a graph showing the actual development of the trade balance of the Czech Republic and the PRC, as well as the development of predictions using individual generated and preserved networks. 
The chart shows that all neural networks predict the development of the trade balance at different intervals differently. However, the similarity between predictions of individual networks, but similarity (or degree of consistency) with actual trade balance developments is not important.

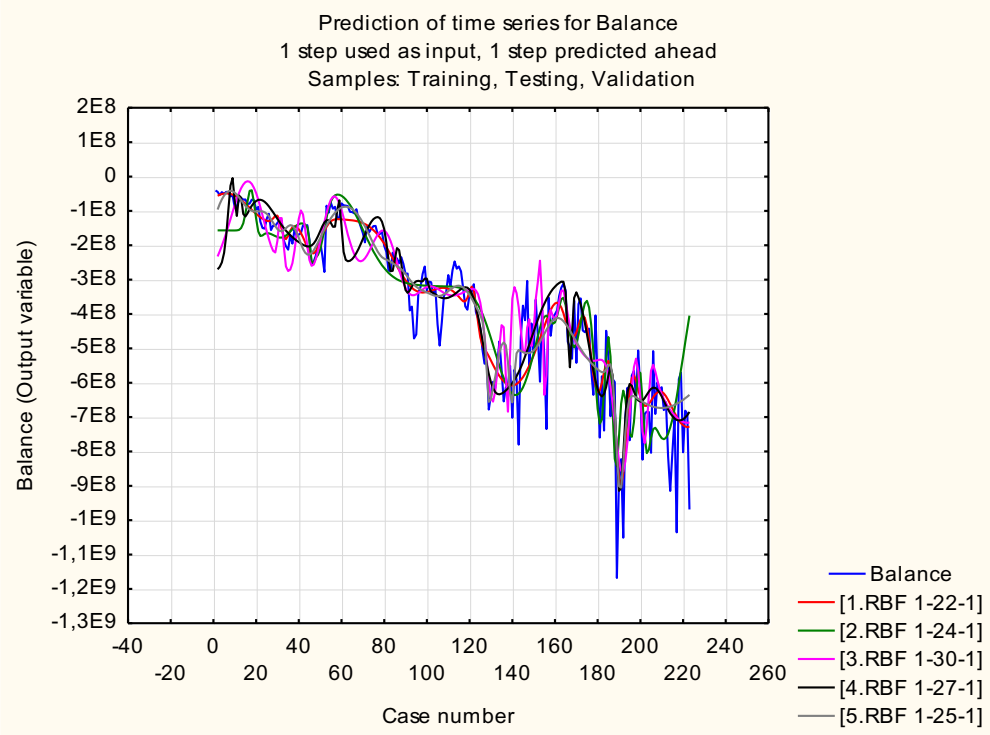

Fig. 8 Line graph - The Czech Republic and the PRC trade balance predicted by neural networks compared to the real trade balance in the monitored period Source: Authors.

If we examine the course of the individual curves and their consistency with the real course of the trade balance between the Czech Republic and the PRC, we will come to the following conclusions:

- 1.RBF 1-22-1: aligns the time series fairly well. However, it can not register well local trade fluctuations.

- 2.RBF 1-21-1: offers a very similar pattern to network number 1 . However, it exceeds the acceptable error value at the beginning and end of the period under review.

- 3.RBF 1-29-1: aligns time series in a rather interesting way. It tries to register local fluctuations. This, however, is predicted even in cases where there were actually none.

- 4.RBF 1-25-1: has a similar pattern to the curve constructed according to the first neural network. Only in the course of the trade balance at the beginning of the monitored period it shows a large fluctuation from the actual trade balance development.

- 5.RBF 1-24-1: shows the best results. Within a certain tolerance, the trade balance of the Czech Republic and the PRC is fairly well reflected.

\section{Conclusion}

The aim of the paper was to compare the accuracy of time series alignment using regression analysis and neural networks on the example of the trade balance between the Czech Republic and the People's Republic of China. 
In general, each prediction is given by a certain degree of probability with which it is to be fulfilled. As we predict the future development of any variable, we try to estimate the future development of this variable on the basis of previous years' data. Although we can include most of the factors influencing the target variable in the model, we always simplify reality, and we always work with a certain degree of probability that some of the predicted scenarios will be fulfilled As with linear regression, as well as regression using neural networks, there is simplification - and quite substantial. We only work with two variables input (time) and output (trade balance Czech Republic x PRC). So, we completely ignore other input variables, which often have a significant impact on the trade balance between the Czech Republic and the PRC (international political situation, taxation in both countries, production factor prices, state export support, natural resources and many others). The main determinant is then the purpose for which we perform the calculation. If we want to estimate the future development of individual countries' economies based on the trade balance between the Czech Republic and the PRC, it is likely that such simplification will be sufficient and the calculation will have adequate information value. If, for example, we are planning to plan for the shipping capacity of a particular company, it will not be enough to use such simplified time series. It is still true that we estimate aggregated variables better than partial ones.

At the same time, we can state that due to the great simplification of reality, it is not possible to predict the emergence of extraordinary situations and their impact on the Czech Republic and PRC trade balance (perhaps in the short term, yes, but certainly not long term). Ideal would be a prediction for the next few days, but for such a short prediction it is currently not possible to obtain data.

The trade balance of both countries can be determined on the basis of statistical methods, causal methods and intuitive methods. In this case, we have been comparing statistical methods. However, they only gave us a possible framework for the development of the monitored variable. It is important to work with information on the possible future development of the economic, political or legal environment. If we can predict their development, we can then project it into the monitored trade balance. At the same time, however, the personality of the evaluator comes into play - an economist who, on the basis of his knowledge and experience, corrects the price determined by the statistical methods and specified on the basis of causal links.

Optically, the LOWESS curve was the best out of linear regression, followed by the smallest squares curve by negative-exponential smoothing, and the curve obtained by the smallest square-weighed distance. From the neural networks, the network 5.RBF 1-24-1 proved to be the most usable in practice. If we look at performance from a correlation coefficient point of view, the neural network 5.RBF 1-24-1 remains usable. The aim of the paper was fulfilled.

\section{References}

1. J. Drábek, L. Lipková, M. Gress, Development of the balance of payments in the czech republic since 1993 with the emphasis on current account. Economic Annals-XXI, 78(2), 4-7, (2015)

2. R. Martin, Central and eastern europe and the international economy: The limits to globalisation. Europe - Asia Studies, 50(1), 7-26, (1998)

3. M. Engman, Expanding international supply chains: The Role of Emerging Economies in Providing it and Business Process Services. OECD Trade Policy Papers, (52), 66 p., (2007) 
4. O. G. Golichenko, S. Samovoleva, The balance of externalities and internal effects in national innovation systems. Proceeding of the 10th European Conference on Innovation and Entrepreneurship, 223-230, (2015)

5. F. Novotný, Profitability Life Cycle of Foreign Direct Investment: Application to the Czech Republic. Emerging Markets Finance and Trade, 54(7), 1623-1634, (2018)

6. Czech Republic freight transport \& shipping report - Q2 2017, London: Business Monitor International, (2017)

7. T. De Castro, J. Vlčková, P. Hnát, Trade and investment relations between the czech republic and china: The czech republic as a gateway to the EU? Society and Economy, 39(4), 481-499, (2017)

8. Význam zahraničního obchodu s Č́nou roste, Czech Statistical Office [online]. Available at:

https://www.czso.cz/csu/czso/vyznam_zahranicniho_obchodu_s_cinou_roste_2013062 $\underline{7}(2013)$

9. Č́na: Obchodní a ekonomická spolupráce s $\check{C} R$, Ministry of Foreign Affairs [online]. (C) Zastupitelský úřad ČR v Pekingu (Čína). Available at: http://www.businessinfo.cz/cs/clanky/cina-obchodni-a-ekonomicka-spoluprace-s-cr19054.html (2018)

10. R. Gerard, The political economy of transition. The Journal of Economic Perspectives, 16(1), 29-50, (2002)

11. I. T. Y. Chen, Balance of payments and power: assessing China's global and regional interdependence relationship. International Relations of the Asia-Pacific, 14(2), 271302, (2014)

12. Z. P. Hao, Regulation and organisation of accountants in China. Accounting, Auditing \& Accountability Journal, 12(3), 286-302, (1999)

13. A. Ortolani, Chinese begin paying by cellphone. Wall Street Journal [online], pp. 1. Available at: https://search.proquest.com/docview/399037632? accountid=133446 (2005)

14. S. Tseng, Trade flows between czech republic and east asia. Review of Economic Perspectives, 13(3), 146-158, (2013)

15. OECD science, technology and industry scoreboard 2007: Innovation and performance in the global economy (2007). Paris: Organisation for Economic Cooperation and Development (OECD), 228 p. 